\section{Salud y cosmovisión indígena: un derecho colectivo en construcción}

María José Bournissent

Integrante del Programa

de Derechos Humanos.

Universidad Nacional del Litoral.
Universidad y salud /

Intervenciones

\section{Resumen}

Este trabajo tiene la finalidad de reflexionar y esbozar algunas aproximaciones conceptuales en el campo de la salud vinculadas a la cosmovisión indígena. Elementos que han surgido a partir de las intervenciones socioculturales realizadas con comunidades indígenas en el marco de una línea sobre derechos colectivos indígenas del Programa de Derechos Humanos de la Secretaría de Extensión de la UNL.

El reconocimiento en instrumentos jurídicos de la dimensión indígena ha sido un importante avance; sin embargo, la brecha de implementación es amplia y profunda y marca un desfase entre el plano formal y la praxis. El ejercicio del derecho a la salud desde una perspectiva intercultural requiere del desapego de prejuicios y del abandono de la posición hegemónica para adentrarse en un diálogo recíproco entre culturas que valoricen la diferencia para potenciar la igualdad.

\section{Palabras clave}

- prácticas de extensión

- interculturalidad

- comunidades indígenas

- derechos colectivos

- salud y cosmovisión "manifestamos que somos parte de la naturaleza

y el macrocosmos, estamos llamados a cuidarla y defenderla puesto que de ella se desprende nuestra historia milenaria y nuestra cultura que nos hacen ser lo que somos hoy pueblos originarios indígenas, bajo la protección y la guía espiritual de nuestros padres y abuelos que engendraron a todos los seres que habitamos en este maravilloso planeta (...) promovemos el fortalecimiento de las identidades originarias indígenas; y a su vez con las distintas instituciones del Estado y organizaciones en general, convencidos del aporte valioso que podemos dar al proceso de transformación de los pueblos indígenas y de la sociedad en su totalidad, teniendo en miras la construcción de un mundo mejor para todos, en el que prime la armonía, solidaridad y el respeto de la diversidad cultural y de la Madre Tierra"

(Extracto del Manifiesto de San Pedro de Colalao). ${ }^{1}$

El constructo conceptual de interculturalidad ha guiado gran parte de las reflexiones y discusiones políticas y jurídicas en Latinoamérica, tanto en lo que respecta a la recepción y armonización de los derechos colectivos de los pueblos indígenas en el sistema normativo como sobre el diseño e implementación de políticas públicas. Estas disputas comenzaron en el campo de la educación en la década del '90 y permearon al área de la salud. En el caso argentino, el debate se profundizó a partir de la reforma constitucional en 1994, con la incorporación del inciso 17 del artículo 75 sobre los derechos colectivos de los pueblos indígenas en la Carta Magna y con la posterior ratificación del Convenio 169 de la Organización Internacional del Trabajo. ${ }^{2}$

La interculturalidad no es un concepto unívoco y menos aún pacífico. Implica conflicto de poderes en disputa, como todo proyecto político, y propone un diálogo entre culturas desde una posición ius filosófica decolonial y con pie en las culturas locales. Al mismo tiempo, los pueblos indígenas viven la interculturalidad como una práctica social colectiva que sostiene vínculos de complementariedad y reciprocidad entre los hombres, la naturaleza y el cosmos.

La necesidad de impulsar un diálogo intercultural entre pueblos indígenas y universidad permeó en el ámbito de la UNL de la mano
1) Documento elaborado en el marco del Encuentro Espiritual de Mujeres Abuelas, Mayores y Personas de Medicina de Culturas Originarias realizado en Tucumán los días 13, 14 y 15 de mayo de 2014, convocado por la Organización de Naciones y Pueblos Indígenas en Argentina (ONPIA) 2) El Convenio 169 de la Organización Internacional del Trabajo, en su artículo 25, expresa que:
1. Los gobiernos deberán velar para que se pongan a disposición de los pueblos interesados servicios de salud adecuados o proporcionar a dichos pueblos los medios que les permitan organizar y prestar tales servicios bajo su propia responsabilidad y control, a fin de que puedan gozar del máximo nivel posible de salud física y mental.

2. Los servicios de salud deberán organizarse, en la medida de lo posible, a nivel comunitario. Estos servicios deberán planearse y administrarse en cooperación con los pueblos interesados y tener en cuenta sus condiciones económicas, geográficas, sociales y culturales, así como sus métodos de prevención, prácticas curativas y medicamentos tradicionales. 3. El sistema de asistencia sanitaria deberá dar la preferencia a la formación y al empleo de personal sanitario de la comunidad local y centrarse en los cuidados primarios de salud, manteniendo al mismo tiempo estrechos vínculos con los demás niveles de asistencia sanitaria.

4. La prestación de tales servicios de salud deberá coordinarse con las demás medidas sociales, económicas y culturales que se tomen en el país. 


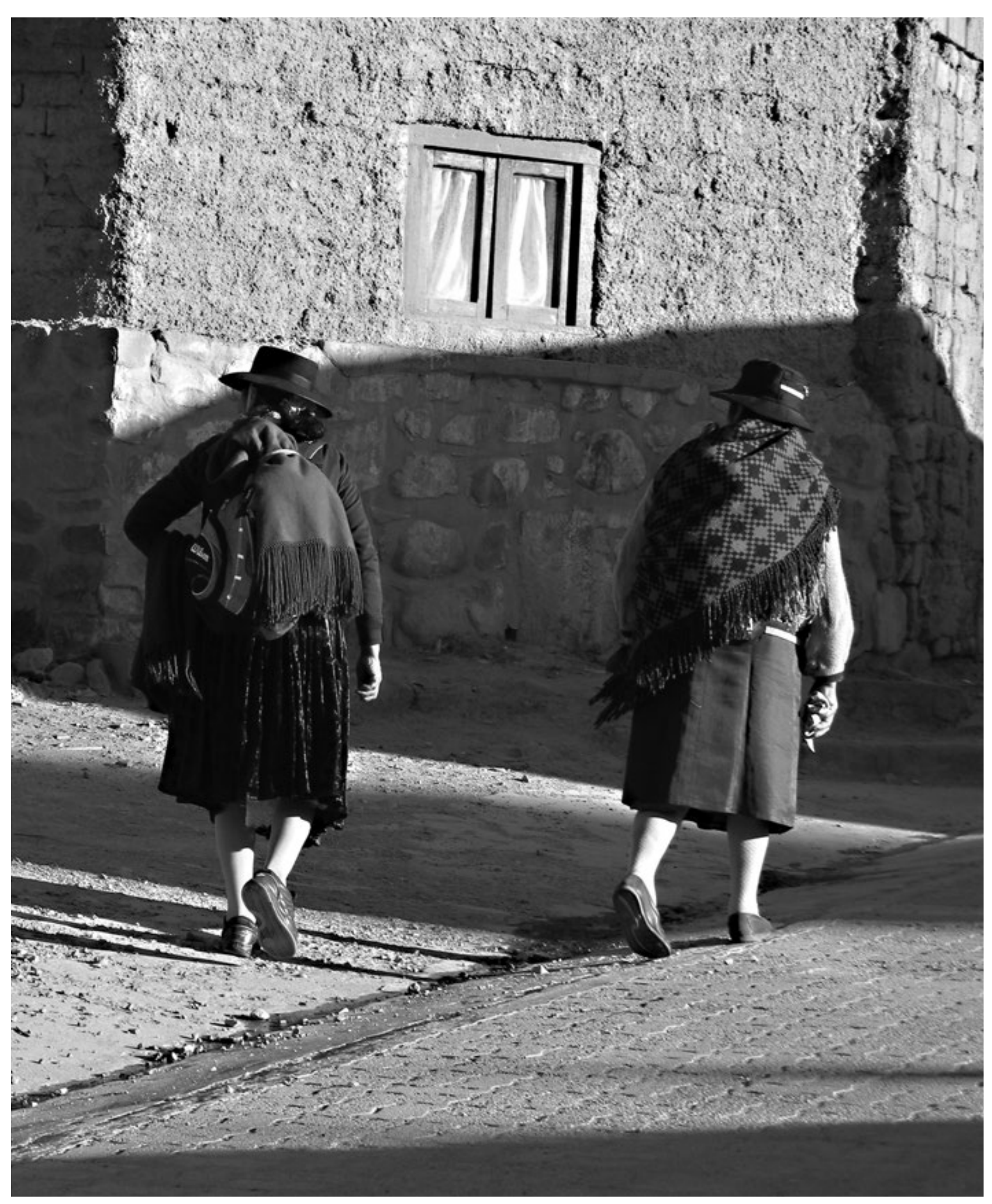


desde el comienzo del proyecto

se firmó un convenio

con el Concejo Municipal

para trabajar en la implementación

de quioscos saludables

en los establecimientos educativos de un equipo de docentes que, en conjunto con la Organización de Comunidades Aborígenes de Santa Fe (OCASTAFE), implementó una serie de prácticas y proyectos de extensión que forjaron una línea de trabajo en el Programa de Derechos Humanos de la Universidad.

El trabajo se fue entretejiendo con diferentes proyectos de extensión con el propósito de dar continuidad al espacio. En el año 2008 se inició "Abriendo caminos. Un trabajo conjunto entre la comunidad mocoví Com Caia y la Universidad"; en 2010, "Construyendo el puente. Educación intercultural entre las comunidades aborígenes de Santa Fe y la Universidad"; en 2012, "Construyendo el puente. Fortalecimiento y continuidad del diálogo intercultural entre las comunidades indígenas y la Universidad Nacional del Litoral", y en 2012 se llevó a cabo el proyecto de extensión de cátedra "La propiedad comunitaria indígena. ¿Un nuevo derecho real?".

Es importante mencionar como prácticas de extensión los sucesivos Encuentros de mujeres indígenas realizados desde el año 2008 como espacio de reflexión, diálogo, producción y creatividad para las mujeres indígenas de la región de Santa Fe, con el objetivo de afianzar la identidad y autoestima para el fortalecimiento de su rol desde la acción política. Los encuentros se efectuaron en la localidad de Recreo en el año 2008, en 2009 en Colonia Dolores, en 2010 en Cayastá, en 2011 en Colastiné Sur, y en 2012 en Helvecia. Complementariamente, se llevaron a cabo en la Facultad de Ciencias Jurídicas y Sociales eventos académicos que posibilitaron ampliar el diálogo con otros actores. Así, en mayo de 2010 se realizó el Seminario "Nuevos desafíos para el cumplimiento de los derechos humanos de los pueblos originarios", organizado juntamente con la Asociación de Abogados/as de Derecho Indígena (AADI); en septiembre de ese mismo año se organizó con la Universidad Nacional de Salta el III Simposio Latinoamericano bajo el lema "Jóvenes en contextos de interculturalidad"; y en 2011 se organizó el ciclo de cine y debate "Derechos humanos de los pueblos originarios e interculturalidad".

Un importante logro se concretó en 2013, cuando el Consejo

Superior de la UNL aprobó la creación de la cátedra electiva
Pueblos originarios en diálogo interdisciplinario, con sede en la Facultad de Ciencias Jurídicas y Sociales. Se conformó así un espacio académico sostenido en el tiempo, integrado por docentes y referentes indígenas, por medio del cual se introduce a los estudiantes en la problemática de los pueblos indígenas desde una mirada crítica, que promueve la reflexión y el diálogo intercultural así como el intercambio de conocimientos.

A la par, se impulsó la colaboración interinstitucional con la finalidad de fortalecer los vínculos entre la Universidad, el Estado y las organizaciones de la sociedad, que tuvo como hecho significativo de carácter histórico la firma del primer convenio de mutua colaboración de una institución académica con OCASTAFE en 2010. No tardaron en sumarse otras instituciones, tales como el Ministerio de Desarrollo Social de la Provincia de Santa Fe, el Instituto Provincial de Aborígenes Santafesinos (IPAS) y, en el año 2013, la Asociación de Abogados/as de Derecho Indígena. La situación problemática abordada en la hilvanada red entre extensión, docencia e investigación, da cuenta de la amplia brecha existente entre la implementación de los derechos colectivos indígenas y el plano normativo, entre las conquistas jurídicas y el terreno de la praxis, y permite comprobar las reiteradas violaciones a los derechos indígenas así como la ausencia de legítimas y fidedignas políticas públicas.

Si bien el eje transversal de todas las actividades son los derechos colectivos de los pueblos indígenas, el derecho a la salud desde el ejercicio de la interculturalidad es una problemática instalada dentro del conjunto de reivindicaciones reclamadas con mayor fuerza por mujeres indígenas. Recientemente, en junio de 2014, se llevó a cabo en la Facultad de Ciencias Jurídicas y Sociales una jornada intercultural "Salud y cosmovisión indígena. Medicina en las culturas originarias", en la que participaron referentes de comunidades mocovíes de Recreo, Colonia Dolores y Helvecia, de comunidades tobas de Rosario y representantes del Ministerio de Salud de la Provincia de Santa Fe.

Las mujeres indígenas expositoras dieron cuenta de las falencias en el camino a un genuino reconocimiento del derecho indígena 
a la salud desde una perspectiva intercultural, identificando la pérdida del uso de plantas medicinales por falta de espacios para cultivarlas o la contaminación del ambiente debido al uso de agrotóxicos en zonas rurales, sumadas a la desvalorización y al no reconocimiento de sus saberes prácticos ancestrales. Otro polo de reclamos se instaló en cuanto a las falencias en los servicios de salud que no tienen en cuenta las prácticas curativas y las medicinas tradicionales, así como la atención deficitaria en hospitales públicos, que se traduce en la falta de agentes sanitarios que actúen como promotores culturales de salud y medien en la relación paciente-médico, incluso ejerciendo el rol de traductor a la lengua materna.

Otro tópico que se debatió atañe a la participación y autogestión ligadas directamente al derecho a la organización y administración de los servicios de salud, particularmente los vinculados a los centros de salud anclados en comunidades indígenas. Ello implica la posibilidad de ejercer el control en el planeamiento y administración cuando hablamos de participación y la iniciativa en la creación del centro sanitario en el caso del derecho a la autogestión, recordando que esos son derechos establecidos en la ley vigente y que su incumplimiento es parte de la brecha de implementación.

Sin dudas, surge a todas luces la necesidad de diseñar una política pública en materia de salud indígena que contemple éstas y otras tantas acciones que pongan en práctica los derechos colectivos relativos a la salud. En este sentido, la existencia de experiencias exitosas aisladas depende, más bien, de buenas voluntades y no de políticas públicas sostenidas.

La búsqueda de herramientas para construir un diálogo entre Universidad y comunidades indígenas que promueva acciones transformadoras desde una perspectiva crítica nos posibilitó el intercambio de conocimientos, sinergia que se facilitó a través de la intervención mediante talleres de educación intercultural con las comunidades. El diálogo en situación de reciprocidad y la observación participativa nos condujeron a comprender que el concepto de salud en la cosmovisión indígena no puede sino interpretarse de manera holística, incluyendo aspectos físicos, emocionales y espirituales, que se relacionan con la concepción del ser - "estando y haciendo" en comunidad y en permanente vínculo con el entorno naturaleza.

En ese sentido la salud es una preocupación que trasciende a la enfermedad y se manifiesta en las formas tradicionales de alimentación; crianza de los hijos; aprendizajes que devienen de la participación en prácticas familiares y transmisiones orales de madres, abuelas y tías.
En entrevista con la dirigente indígena Clara Chilcano (2014), ${ }^{3}$ autoridad de la organización indígena de Santa Fe y delegada para las actividades de extensión, compartió algunas nociones sobre salud y cosmovisión mocoví, de la que resulta interesante transcribir algunos fragmentos, en tanto la voz del indígena legitima cualquier argumentación discursiva:

"Nosotros no podemos negar a nuestros científicos y nuestros sabios tradicionales; son los que curan, previenen las enfermedades y pregonan, cómo, cuándo y por qué; son los conocedores del viento, del mensaje de los pájaros y de los ríos; son los conocedores del sonido del monte... Nuestro pueblo le rinde culto al fuego, porque a su alrededor nuestros ancianos ejercían y ejercen las enseñanzas, donde transmiten su sabiduría... Nosotros agradecemos al río por la pesca, a los montes por la recolección y la caza; y realizamos el saludo a los cuatro vientos. En nuestra cosmovisión todo componente de la naturaleza tiene una parte material y otra espiritual, así el río tiene su dueño que es el "Veraik" y hay que pedirle permiso para bañarse o pescar; el monte también tiene su dueña y es la "Conaya", a ella hay pedirle permiso para entrar... Mis ancestros me han dejado muchos conocimientos sobre hierbas medicinales y algunas curaciones secretas transmitidas de generación en generación.

"Desde la cosmovisión, se habla de la complementariedad del hombre y la mujer, formando un mismo ser donde cada uno tiene su misión espiritual, que tiene que ver con mantener el equilibrio del cosmos. La mujer indígena esta llamada a mantener y contribuir al desarrollo sostenible y conservación de la diversidad biológica y en esta tarea la salud y la educación son temas prioritarios por los cuales luchan las mujeres indígenas." "Los pueblos indígenas enfrentamos una violencia epistémica en la sociedad occidental que se extiende y se reproduce en el sistema educativo y en el sistema de salud, en los cuales se desjerarquiza e invisibiliza el conocimiento indígena, degradándolo como saberes de sentido común o folclorismo. Prejuicios en la comunidad académica y científica que ponen trabas al dialogo intercultural. Debemos desaprender para aprender juntos. Nosotros como pueblos indígenas hemos enfrentado una historia de luchas y resistencias que nos exigieron dinamismo y la capacidad de fortalecer nuestros conocimientos y redefinirnos a partir del contacto con otras culturas."

Creemos necesario continuar promoviendo los canales de diálogo intercultural, que tengan por finalidad compartir saberes, analizar,
3) Agradecemos la permanente disposición de Clara Chilcano para construir en conjunto un puente entre culturas que nos permite ir diseñando acciones que propician y favorecen el diálogo intercultural, teniendo como finalidad impactar en las políticas públicas para encoger la brecha entre el reconocimiento jurídico de los derechos colectivos y su implementación en vida de los pueblos indígenas y sus comunidades. 


\section{6}

los pueblos indígenas

enfrentamos una violencia epistémica

en la sociedad occidental

que se extiende y se reproduce

en el sistema educativo

y en el sistema de salud

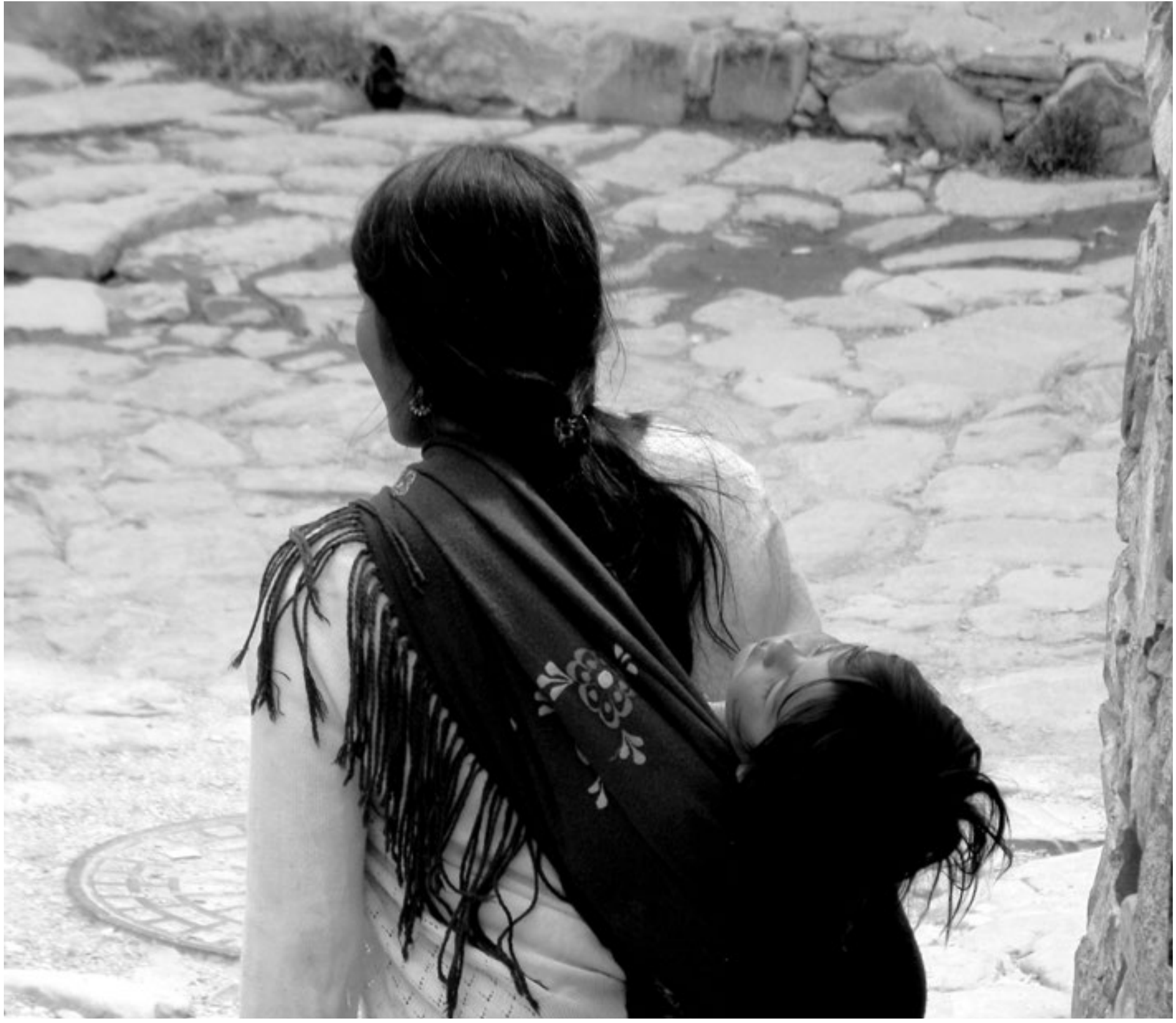


debatir y reflexionar, para propiciar la construcción colectiva de políticas públicas en materia de salud indígena; involucrando ineludiblemente en el proceso de interculturalidad a los miembros y referentes de comunidades indígenas, así como al Estado en sus distintos niveles de organización política.

La base estructural del diálogo es la mirada interdisciplinaria; para la cual se parte del reconocimiento de la incompletud de la propia disciplina. La búsqueda de respuestas a los problemas necesita de la interacción de la antropología, la historia, el derecho, la sociología, la política, la medicina y la psicología, rompiendo con la hegemonía de una ciencia sobre otra. Asimismo resulta imprescindible ingresar en el conocimiento de la cosmovisión indígena para entender lógicas y quehaceres diferentes.

El trabajo en todos estos años nos ha permitido problematizar acerca de la salud y la interculturalidad; disipar el sentido y alcance de la normativa que protege a los pueblos y comunidades indígenas, indagar cuáles son los posibles modos de interacción de indígenas y no indígenas, y pensar cómo se puede garantizar la protección efectiva de sus derechos; así como discutir sobre potenciales políticas públicas en materia de salud indígena que tengan en cuenta en su planificación las peculiaridades locales sin alejarse de la realidad sociocultural y antropológica. A la postre es también necesario profundizar el diálogo con los profesionales de la salud para que conozcan y reconozcan las particulares formas de sanar, alejadas del ortodoxo desempeño diario pero que conforman un marco real y efectivo de ejercicio de la medicina ancestral.
La universidad ha generado un nutrido vínculo con pueblos y comunidades indígenas, a través del cual, si miramos en retrospectiva y comparamos la situación previa con el actual contexto de relación, se han logrado positivos y probados avances, en tanto visibilidad de la problemática, empoderamiento de referentes y dirigentes indígenas, intercambio de saberes y experiencias en el ámbito académico y en diálogo con el Estado. En esta línea de resultados, es trascendental el cambio producido en mujeres indígenas que comenzaron su participación desde un tímido y avergonzado aporte en los talleres y encuentros regionales, impensable en aquel entonces que pudieran escucharse hoy valorizando sus conocimientos sobre prácticas ancestrales adquiridas en el hábitat familiar, así como transmitiendo sus saberes asociados al uso de la palabra y a plantas medicinales para aplicarlos a procesos de sanación. Más bien, estas experticias eran ocultadas y absolutamente invisibilizadas. A lo largo de todos estos años las mujeres indígenas fueron asumiendo progresivamente el uso de la palabra en público, conquistando espacios de poder en el discurso académico y empoderándose de herramientas jurídicas para intervenir en el debate político. Estas ventajas nos impulsan a continuar el trabajo conjunto en tránsito hacia un horizonte posible: el del verdadero ejercicio de la interculturalidad para reconocernos, valorizarnos y complementarnos en pos de la dignidad de la persona humana, no relegando el derecho a la igualdad pero integrándolo con el reconocimiento del derecho a la diferencia, que permita la convivencia de culturas en una sociedad que se pergeña pluricultural.

\section{Bibliografía}

Briones, C. (comp.) (2008). Cartografía Argentina. Políticas indigenistas y formaciones provinciales de alteridad. Buenos Aires: Antropofagia.

Lajo, J. (2005). Qhapaq Ñan: La Ruta Inka de la Sabiduría. Lima: Amaro Runa. Martínez Sarasola, C. (2005). Nuestros paisanos los indios. Buenos Aires: Emecé Editores SA.

Perez De Nucci, A. (2005). La Medicina tradicional del Noroeste argentino. Historia y presente. Buenos Aires: Ediciones del sol.

Quijano, A. (1991). Colonialidad y Modernidad/Racionalidad. Perú: Indígena.

Ramírez, S. (2008). "Derechos de los pueblos indígenas: protección normativa, reconocimiento constitucional y decisiones judiciales". En: R. Gargarella (ed.), Teoría y Crítica del Derecho Constitucional. Buenos Aires: AbeledoPerrot.

Rivera Cusicanqui, S. (2011). Una reflexión sobre prácticas y discursos descolonizadores. Buenos Aires: Tinta Limón.

Salgado, J.M. y Gomiz, M.M. (2010). Convenio 169 de la OIT sobre pueblos indígenas: su aplicación en el derecho interno argentino.

Sousa Santos, B. (2010). Para descolonizar Occidente. Buenos Aires: Clacso. Tamagno, L. (coord.) (2009). Pueblos indígenas: interculturalidad, colonialidad, política. Buenos Aires: Biblos. 